\title{
Expression of Ki-67 and p53 in meningiomas
}

\author{
S. PAVELIN ${ }^{1}$, K. BECIC ${ }^{2}$, G. FOREMPOHER ${ }^{3}$, I. MRKLIC $^{3, *}$, Z. POGORELIC ${ }^{4}$, M. TITLIC 1 , S. ANDELINOVIC ${ }^{3}$
}

${ }^{1}$ Department of Neurology, Split University Hospital Centre, University of Split, School of Medicine, Spinciceva 1, Split, Croatia; ${ }^{2}$ University of Split, School of Medicine, Soltanska 2, Split, Croatia; ${ }^{3}$ Department of Pathology, Forensic Medicine and Cytology, Split University Hospital Centre, University of Split, School of Medicine, Spinciceva 1, Split, Croatia; ${ }^{4}$ Department of Pediatric Surgery, Split University Hospital Centre, University of Split, School of Medicine, Spinciceva 1, Split, Croatia

${ }^{*}$ Correspondence: ivana.mrklic@mefst.hr

\section{Received December 6, 2012/ Accepted February 18, 2013}

\begin{abstract}
Meningiomas account for about $30 \%$ of all primary brain tumors. It is difficult to predict the behaviour of meningiomas, and identification of protein markers responsible for the regulation of cell proliferation can be very helpful. The aim of this study was to evaluate immunohistochemical expression of Ki-67 and p53 in 170 meningiomas.

A total number of 170 meningioma samples were classified according to WHO, immunohistochemicaly stained for Ki-67 and 553 and analysed using light microscope.

Of 170 meningiomas analysed, 142 were grade I, 17 grade II and 11 grade III. Female to male ratio was 1.42:1. Statistically significant correlation was found between tumor grade and Ki-67 ( $<<0.001)$. There was significant correlation between Ki-67 levels and tumor subtypes ( $\mathrm{p}=0.009)$. The optimal cut-off value for Ki-67 was 3.195 . Tumors with Ki-67 $\leq 3.195$ were $2 \mathrm{~cm}$ smaller than tumors with Ki-67 $>3.195$. Statistically significant correlation was found regarding p53 expression and tumor size $(\mathrm{p}=0.034)$. No correlation was established between Ki-67 or $\mathrm{p} 53$ and location of the tumor.

According to positive correlation between tumor grade and subtype with $\mathrm{Ki}-67$ levels, as well as positive correlation between Ki-67 and p53 with tumor size, indicate that Ki-67 and p53 might have influence on meningioma development and progression.
\end{abstract}

Key words: meningioma, Ki-67, p53, immunohistochemistry

Meningiomas are common tumors of the central nervous system that originate from the meningeal coverings of the brain and the spinal cord $[1,2]$. Although most meningiomas are benign, they have a surprisingly broad spectrum of clinical characteristics and histologically distinct subsets are associated with high risk of recurrence, even after complete resection. In rare instances, meningiomas are malignant [3]. About 80\% meningiomas are slow-growing tumors of WHO grade I, and most commonly diagnosed histological subtypes are meningothelial, fibrous and transitional meningioma. Following gross total resection, benign meningiomas are associated with 5 -year recurrence rates of 5\%. Atypical meningiomas constitute $15-20 \%$ of meningiomas and are associated with 5-year recurrence rates of $40 \%$ for totally resected tumors. Anaplastic meningioma account for 1-3\% of all meningioma cases and have clinical characteristics similar to other malignant neoplasms [4]. WHO grade I meningiomas are expected to have a benign course. The behaviour of meningiomas is difficult to predict, and identification of protein markers responsible for the regulation of cell proliferation can be very helpful. Ki-67 antigen is protein expressed only in proliferative phase of cell cycle, and can be detected on formalin fixed paraffin embedded tissue sections. Proliferation index measured by Ki- 67 may be used as an objective method for predicting tumor behaviour [5-9]. Multiple factors are involved in tumor progression and one of them is mutation of tumor suppressor gene p53. Wild type gene product functions as a transcription factor and is involved in DNA repair regulation of cell cycle and induction of apoptosis. Mutated p53 lacks these properties leading to genomic instability and is a frequent target for genetic abnormalities in most tumors. Mutation of $\mathrm{p} 53$ gene results in metabolically stable abnormal protein that accumulates in the nucleus reaching the level to be easily detected by immunostains. Expression of p53 protein in tissue section is an indicator of possible mutation in p53 gene itself $[10,11]$. In the present study, we aimed to investigate the immunohisto- 
chemical profile of meningiomas by using Ki-67 and p53 as markers with established roles in tumor progression and to determine the association of these markers with histological grade and subtype.

\section{Patients and methods}

The histological sections of 170 patients (70 (41\%) men and 100 (59\%) women) with totally resected meningiomas, diagnosed at the Department of Pathology, Split University Hospital Centre, between January 2000 and December 2010, were retrospectively reviewed.

Tumor size was obtained from neuroradiographic (MSCT) images. All clinical data were collected from the clinical history charts.

The surgical specimens were fixed in $10 \%$ buffered neutral formalin, entirely sampled, and embedded in paraffin. A $5-\mu \mathrm{m}$ sections were stained with haematoxylin and eosin (H\&E). All histological and immunohistochemical (IHC) tumor slides were evaluated by experienced pathologist (G. F.), and regrouped as benign, atypical, and anaplastic meningiomas according to the WHO classification of tumors of the central nervous system (3).

Representative slide of each case was selected for additional IHC analysis for p53 and Ki-67, performed on automated Ventana stainer (Ultra Benchmark Ventana, Tucson, Arizona).

For p53 detection we used DO-7, Dako, Denmark at dilution 1:100. It was incubated for $32 \mathrm{~min}$ and after that heated in $\mathrm{CC} 1$ for $36 \mathrm{~min}$ on $95^{\circ} \mathrm{C}$. The same procedure was performed for Ki-67 for which we used MIB-1, Dako, Denmark at dilution 1:200.

Tissue sections were evaluated by using Olympus BX41 light microscope with $\times 40$ objective equipped with an ocular grid.

For Ki-67 and p53, cells with brown nuclear staining were considered positive. Ki-67 and p53 expression were defined as percentage of positive cells, determined by using Cell D1 Image analysis (Olympus, Soft Imaging System GmbH, Munster, Germany) by counting at last 1000 tumor cells in fields with the largest number of positive cells (Fig. 1,2).

Statistical analysis. Obtained data were analyzed by using Statistics for Windows Release 12.0 (Statsoft, Tulsa, Oklahoma, USA). All p values of less than 0.05 were considered to indicate statistical significance. All statistical tests were two-sided, with the confidence interval of $95 \%$. Correlations between categorical variables were studied using chi-square and Mann-Whitney U test. The optimal cut-off value for Ki- 67 was selected by using receiver operating characteristic (ROC) method, and tumors were divided in two groups according to Ki-67 levels ( $\leq 3.195$ and $>3.195$ ). For p53 levels we used two criteria for division. First categorisation was created by statistical analysis and $\mathrm{p} 53$ percentages were grouped in three categories ( 0 - none, $\leq 25$ - low and $>25$ - high). For second categorisation $10 \%$ was used as arbitrary cut-off value, experience based. We noticed that tumors with p53 levels higher than $10 \%$ have more aggressive clinical behaviour. $\mathbf{a}$

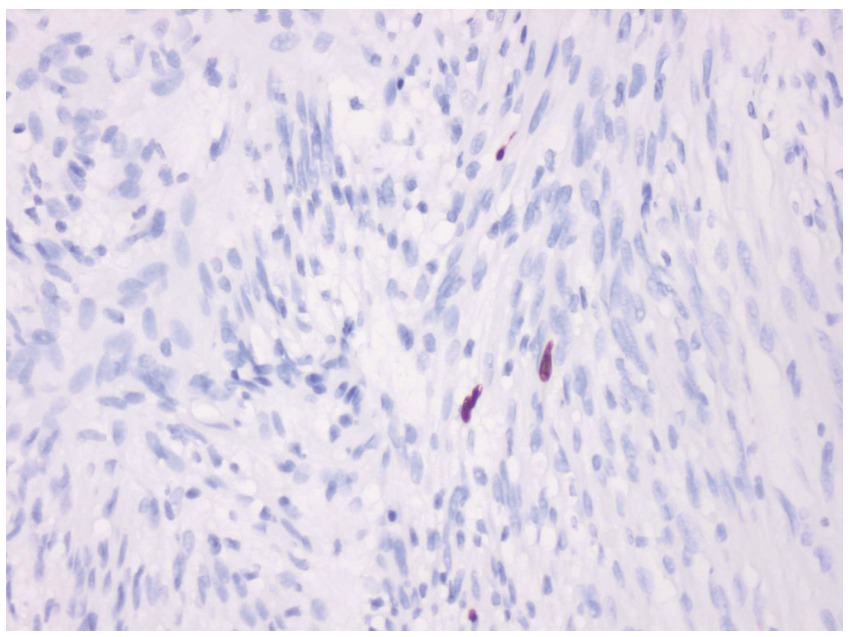

b

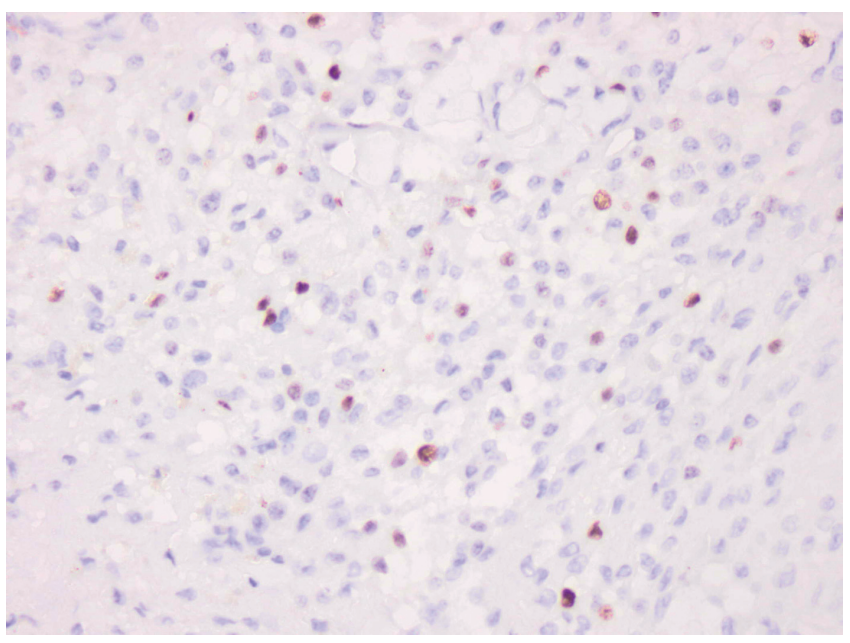

C

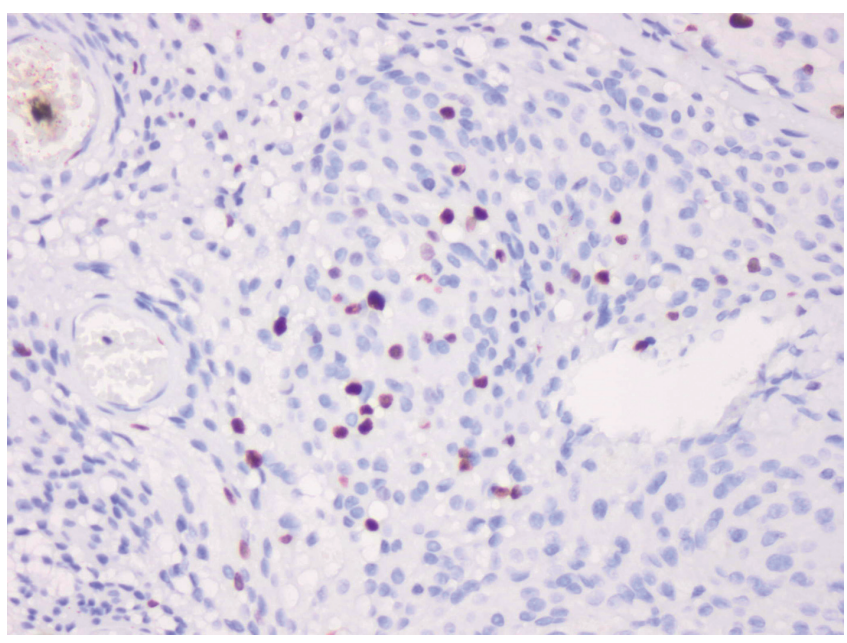

Figure 1. Immunohistochemical staining of Ki-67 antibody in different grade meningiomas: (a) grade I; (b) grade II; (c) grade III (40x). 
a

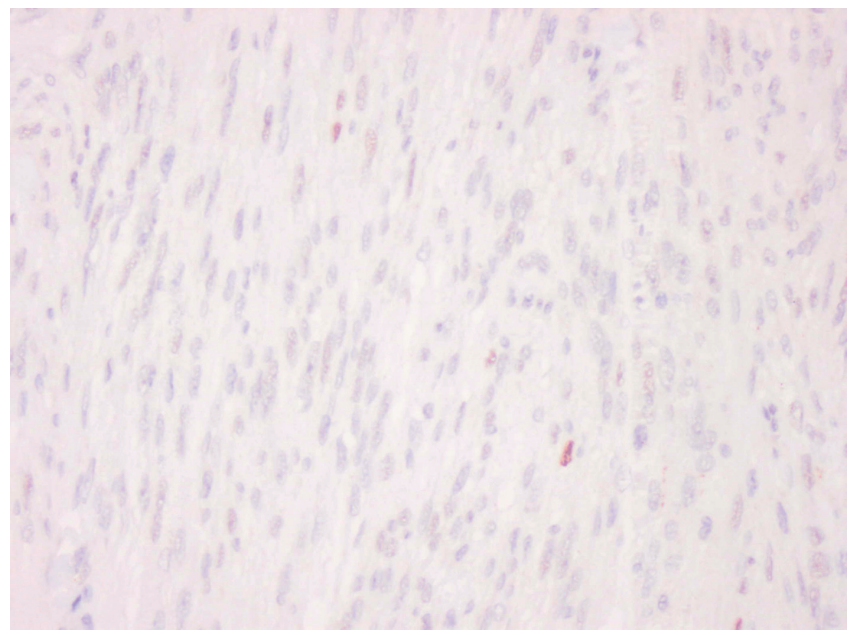

b

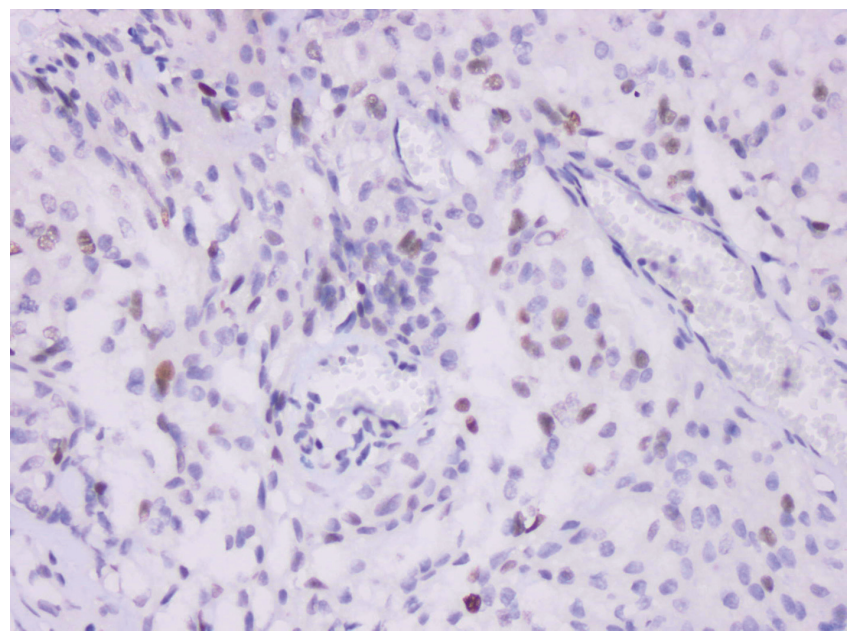

C

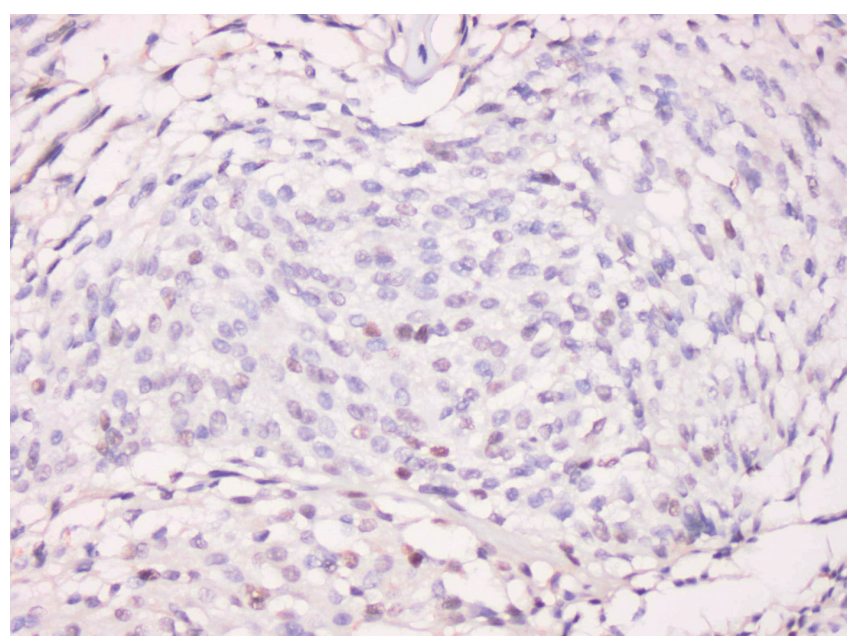

Figure 2. Immunohistochemical staining of p53 antibody in different grade meningiomas: (a) grade I; (b) grade II; (c) grade III (40x).

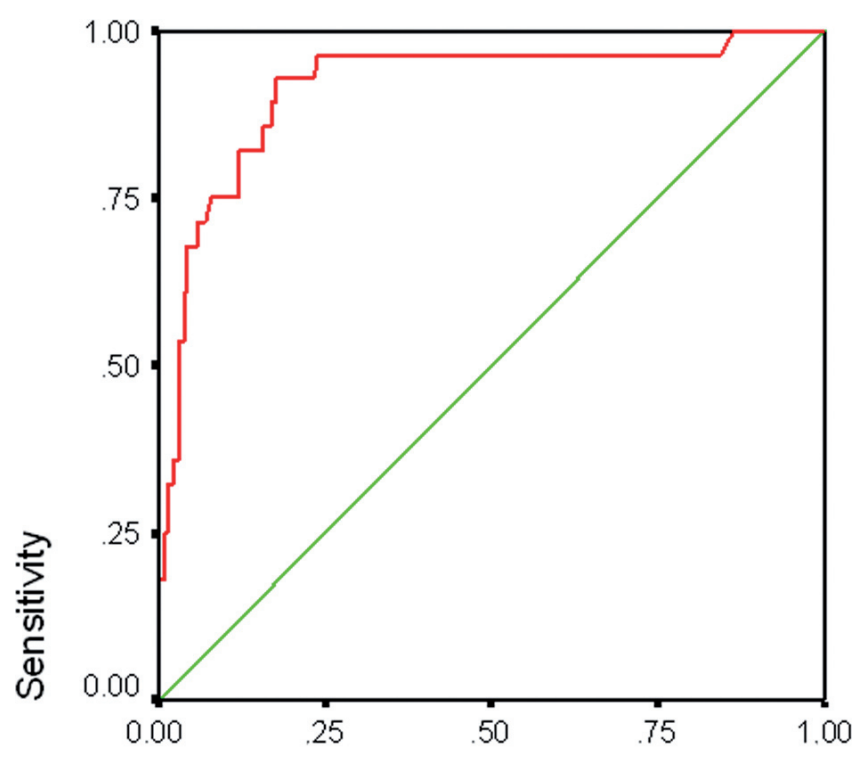

\section{1 - Specificity}

Figure 3. ROC curve. The optimal cut-off value for Ki-67=3.195\%, sensitivity $92.9 \%$; specificity $82.4 \%$ (area 0.917 , SE $0.033,95 \%$ CI $0.853-0.981$, $\mathrm{p}<0.001)$.

\section{Results}

Occurrence of meningioma was more common in female than in male patients (ratio 1.42:1). In women there were 3 times more benign tumors than atypical and anaplastic, while in men there were 2 times more atypical and anaplastic meningiomas $(\mathrm{P}<0.001)$. In the group of fibroblastic meningiomas there were 2.7 times more women than men $(\mathrm{P}=0.22)$. The age of patients at the time of surgery varied from 19 to 85 years (median 68). Average age at surgery for male patients was 68.5 years (19-85), and female 67.5 years (36-83). There was no significant correlation regarding age and meningioma grade $(\mathrm{p}=0.218)$ (Table 1$)$. Statistically significant correlation between tumor grade and Ki-67 expression $(\mathrm{P}<0.001)$ was found. Between tumors with grade II and grade III median for Ki-67 differed 1.6 times $(\mathrm{p}<0.032)$

Median for Ki-67 was 5.2 times lower in the group with grade I than in group with grade II and III together $(\mathrm{p}<0.001)$. Statistically significant correlation between p53 levels and tumor grade was not found $(\mathrm{p}=0.292)$. However, there were 1.6 times more tumors with $\mathrm{p} 53$ higher than $10 \%$ in the group with grade II and III together than in group with grade I tumors $(\mathrm{P}=0.077)$. Statistically significant correlation between tumor size and grade was found $(\mathrm{P}<0.001)$.

The optimal cut-off value for Ki-67 was 3.195\%, with sensitivity $92.9 \%$ and specificity $82.4 \%$ (area 0.917 , SE $0.033,95 \%$ CI 0.853-0.981, p<0.001) (Fig. 3).

Distribution of Ki-67, p53 expression and tumor size according to meningioma grade are presented in Table 2. 
Table 1. Patients statistics and tumor characteristics.

\begin{tabular}{|c|c|c|c|c|}
\hline & \multicolumn{3}{|c|}{ Grade } & \multirow[b]{2}{*}{ Total } \\
\hline & I & II & III & \\
\hline M:F ratio & 49:93 & $14: 4$ & $7: 3$ & $70: 100$ \\
\hline Age & $68(36-83)$ & $72(44-83)$ & $73(19-85)$ & $68(19-85)$ \\
\hline Meningothelial & $12(8.5 \%)$ & $4(22.2 \%)$ & $1(10 \%)$ & $17(10.0 \%)$ \\
\hline Fibroblastic & $57(40.1 \%)$ & $5(27.7 \%)$ & $1(10 \%)$ & $63(37.1 \%)$ \\
\hline Transitional & $48(33.8 \%)$ & $7(38.88 \%)$ & 0 & $55(32.4 \%)$ \\
\hline Angiomatose & $8(5.6 \%)$ & 0 & 0 & $8(4.7 \%)$ \\
\hline Metaplastic & $1(0.7 \%)$ & 0 & 0 & $1(0.6 \%)$ \\
\hline Secretory & $10(7.0 \%)$ & 0 & 0 & $10(5.9 \%)$ \\
\hline Microcystic & $1(0.7 \%)$ & 0 & 0 & $1(0.6 \%)$ \\
\hline Psamous & $5(3.5 \%)$ & 0 & 0 & $5(2.9 \%)$ \\
\hline Papillary & 0 & 0 & $8(80.0 \%)$ & $8(4.7 \%)$ \\
\hline Clear cell & 0 & $2(11.11 \%)$ & 0 & $2(1.2 \%)$ \\
\hline Total & $142(100.0 \%)$ & $18(100.0 \%)$ & $10(100.0 \%)$ & $170(100.0 \%)$ \\
\hline
\end{tabular}

Table 2. Distribution of Ki-67, p53 expression and tumor size according to meningioma grade.

\begin{tabular}{lccc}
\hline & Grade I & Grade II & Grade III \\
\hline Ki-67 $(\%)$ & $1.5(0-13.9)$ & $6.2(0.3-13.5)$ & $10.2(3.4-42.1)$ \\
p53 & $0(0-99)$ & $12.8(0-95)$ & $15.6(0-80)$ \\
Tumor size $(\mathrm{cm})$ & $3(0.5-9)$ & $5(2.5-9)$ & $5.5(2-10)$ \\
\hline
\end{tabular}

* Kruskal Wallis

Tumors with Ki-67 value $\leq 3.195$ were $2 \mathrm{~cm}$ smaller in diameter than those with Ki-67> $3.195(\mathrm{P}<0.001)$ (Table 3). Statistically significant correlation regarding sex and Ki-67 expression was not found $(\mathrm{p}=0.174)$ (Table 3 ). There was a statistically significant correlation between Ki-67 expression and tumor subtype ( $\mathrm{p}=0.009$ ), and the highest Ki-67 expression was found in meningothelial subtype (Table 4).

Distribution of p53 expression in meningiomas is presented in Table 4. Analyzing a group with grade II and III tumors there were 10 tumors with $\mathrm{p} 53=0,11$ tumors with $\mathrm{p} 53=0-25$, and 7 with the values of $\mathrm{p} 53>25$. All $\mathrm{p} 53$ values are more frequent in the grade I group than in grade II and III group together $(\mathrm{P}=0.087)$.

Tumors with $\mathrm{p} 53$ values $<10$ were $0.5 \mathrm{~cm}$ smaller in diameter compared to those in $\mathrm{p} 53>10$ group $(\mathrm{P}=0.034)$. These tumors also had $0.7 \%$ lower median for Ki-67 $(\mathrm{P}=0.039)$. The incidence of $\mathrm{p} 53>10$ was 1.4 times higher in the group of tumors with Ki-67 >3.195 $(\mathrm{P}=0.111)$

Of 170 meningiomas analysed in this paper only 20 were located in posterior of the skull and spine and only one of them had Ki-67>3.195. All the patients with meningiomas in posterior of the skull were female, and $60 \%$ of meningiomas in the posterior of the skull had p53 levels $>10 \%$. There was a significant correlation between tumor localization and tumor subtype ( $\left.\chi^{2}=12.98, p=1.011\right)$, but there was no significant correlation between tumor location and Ki-67 $\left(\chi^{2}=7.3, p=0.026\right)$ and p53 levels $\left(\chi^{2}=0.672, p=0.715\right)$.

\section{Discussion}

Most of meningiomas are benign, up to $80 \%$. Atypical and anaplastic meningiomas have more aggressive clinical behaviour. The histological parameters defined by WHO may sometimes be insufficient to predict aggressive behaviour of some grade I meningiomas. The actively proliferating meningiomas have a higher tendency of recurrence. Almost all studies showed a positive correlation between Ki-67 proliferating marker and tumor grade in meningiomas $[8,12]$. For benign meningiomas the estimated mean for Ki-67 is 3\%, with range from $1-16 \%$. For atypical meningioma the average value is higher $(8 \%)$, with range from $2-20 \%$ [6, 7]. Grade III meningiomas had an average value of $17 \%$, ranging from 7 $32 \%$. Recurrent meningiomas have higher proliferative index with an average Ki-67 value of $4 \%$ (range 0-35\%) [12]. The present study established a strong correlation between Ki-67

Table 3. Correlation of age, sex and tumor size according to Ki-67 value.

\begin{tabular}{lccc}
\hline & Ki-67 $\leq 3.195$ & Ki-67>3.195 & $\mathrm{p}$ \\
\hline Sex male & 45 & 25 & $0,174^{*}$ \\
female & 74 & 26 & \\
Age & $68(36-83)$ & $68(19-85)$ & $0.725^{\star *}$ \\
Tumor size $(\mathrm{cm})$ & $3(0.5-9)$ & $5(1-10)$ & $0.001^{\star *}$ \\
\hline
\end{tabular}

${ }^{*} \chi^{2}$ test; ${ }^{* *}$ Mann Whitney 
Table 4. Distribution of Ki-67 and p53 expression in most frequent meningioma subtypes.

\begin{tabular}{|c|c|c|c|c|}
\hline & Meningothelial & Fibroblastic & Transitional & $\mathrm{p}$ \\
\hline Ki-67 (\%) & $3.25(0.66-10.2)$ & $1.39(0-42.1)$ & $2.3(0-13.5)$ & $0.009^{*}$ \\
\hline Ki-67 (\%) $\leq 3.195$ & $8(47.1)$ & $49(77.8)$ & $40(72.7)$ & $0.043^{* *}$ \\
\hline$>3.195$ & $9(52.9)$ & $14(22.2)$ & $15(27.3)$ & \\
\hline p53 (\%) 0 & $9(52.9)$ & $39(61.9)$ & $24(43.6)$ & $0.123^{* *}$ \\
\hline$\leq 25$ & $6(35.3)$ & $9(14.3)$ & $14(25.5)$ & \\
\hline$>25$ & $2(11.8)$ & $15(23.8)$ & $17(30.9)$ & \\
\hline
\end{tabular}

${ }^{\star}$ Kruskall-Wallis, ${ }^{* *} \chi^{2}$ test

and the histological grade of the meningiomas. The difference in Ki-67 among benign, atypical and anaplastic meningiomas was statistically significant. These results are consistent with previous reports $[6,7,12]$. This finding confirms larger size of the tumors of higher stages in our study. We have attempted to identify the most discriminating value for Ki-67 using a ROC analysis. The selected cut-off value for Ki-67 was 3.193, which is in concordance with the previously estimated Ki-67 value for grade I meningiomas. In order to reduce inter-observer variability, Ki-67 expression in our study was assessed by counting 1000 tumor cells in the fields with the highest proliferative activity by using image analysis. Since benign and atypical meningiomas both show low proliferative activity (3\% vs. $8 \%$ ), and the ranges estimated by WHO significantly overlap, the precise determination of $\mathrm{Ki}-67$ proliferative index is of major importance for determining correct diagnosis, especially in borderline atypical cases when mitoses are difficult to find and other minor histological criteria are scant. We found statistical significant difference between meningioma subtypes and Ki-67 expression, and the significance was maintained when subtypes were grouped according to selected cut-off. Meningothelial meningiomas had the highest median value for Ki-67. Tumor cells of meningothelilal meningiomas resemble normal arachnoidal cap cells, they are large, with uniform oval nuclei and delicate chromatin that on occasion show central clearing, or the formulation of cytoplasmic-nuclear inclusions. Large uniform arachnoidal-like cells may be responsible for those differences between subtypes of meningiomas because appearance of these cells is different in different meningioma subtypes. This observation could provide an additional explanation for the understanding of the recurrence of benign meningiomas, despite the presumed total resection. In our study significantly different Ki-67 expression was found in different meningioma subtypes. This is new and potentially important finding that can offer explanation for differences between meningioma subtypes and their possible future behaviour.

P53 is responsible for tumor progression in many malignant tumors. Earlier studies have demonstrated variable results with regards to alteration of $\mathrm{p} 53$ pathway in meningiomas $[13,14]$. It is generally considered that changes in p53 gene are not often in meningiomas. In our study, the levels of p53 were analysed in relation to meningioma subtypes. Biros et al. showed no significant difference in Arg72Pro polymorphism of p53 gene in meningiomas and astrocytomas [15]. Almeida et al. studying the extra axial brain tumors found TP53 gene methylation in $48 \%$ of malignant tumors. They concluded that the methylation of TP53 is essential for tumor formation and progression, as this leads to inactivation of the p53 suppressor gene [16]. The function of p53 may not be associated only with a gene that encodes it, but could also be dependent on changes in the mechanisms that control it. Al-Khalaf et al. have shown a disorder in p53 and p21 in response to $\gamma$-rays in meningioma cells, with still preserved response to UV rays, which means that the TP53 gene is conserved [17]. This shows that the changes for p53 are not always a result of gene mutations, but rather a consequence of changes in positive regulators of protein 53 . However, the change of $\mathrm{p} 53$ protein, along with other suppressor proteins, can be considered as an important tumorigenous factor in meningiomas. $\mathrm{P} 53$ protein association with histological grade of meningioma has been extensively studied. Results showed wide range of p53 immunoreactivity in meningiomas that varied from $10-88 \%$. P53 immunoreactivity was also correlated with histological degree in relapsed meningioma [18]. Rao et al. created a set of grade I meningiomas which despite the benign histological characteristics, tend to recur due to high levels of expression of $\mathrm{p} 53$ and Ki-67 proteins [19]. Terzi et al. showed that $1 \%$ increase in $\mathrm{p} 53$ labeling index resulted in a 2.17-fold enhanced risk of upgrading a tumor [20]. We did not found statistically significant association between p53 levels and meningioma grade, but it was evident that the median value for $\mathrm{p} 53$ increases with grade of the tumor. Perry and colleagues found also tendency for higher p53 values in higher grades of meningiomas [21]. The highest incidence of negative p53 was found in fibrous subtype of meningioma in which we found the lowest $\mathrm{Ki}-67$ median. According to this finding, fibrous meningiomas might have the smallest tumorigenous potential. The fact that there is positive correlation between tumor localization and tumor subtype is probably because transitional subtype was less common in posterior of the skull and spine, and fibroblastic and transitional subtype occurred more in frontotemporoparietal region. The answer could be found in the fact that the encephalic meninges originate from mesenchyme and the encephalic neural crest while the meninges of the caudal 
regions of the head and spine originate from paraxial mesenchyme. Based on these observations, fibrous meningiomas with the low expression of p53 and $\mathrm{Ki}-67$ are expected to show the least tendency of recurrence, while the meningothelial meningiomas in which the highest Ki-67 expression was found, require caution in clinical management due to possible unexpected behaviour.

\section{Conclusion}

Histological features of malignancy correlate well with proliferation index assessed by using the cell proliferation marker Ki-67. Although p53 levels do not statistically correlate with these features we found that they are higher in largest tumors. Also, positive correlation between tumor grade and $\mathrm{Ki}-67$ levels was established in our study as well as correlation with meningioma subtype. Hence, tumors with an increased proliferative potential grow more rapidly and more likely achieve larger sizes. This could be related with the larger mean size of atypical and malignant lesions found in the present study. Based on our results, expression of Ki-67 and p53 might have influence on meningioma grade and subtype.

\section{References}

[1] CORDERA S, BOTTACCHI E, D'ALESSANDRO G, MACHADO D, DE GONDA F, et al. Epidemiology of primary intracranial tumors in NW Italy; stable incidence in the last two decades. J Neurol 2002; 249: 281-284. http://dx.doi. org/10.1007/s004150200005

[2] KORHONEN K, SALMINEN T, RAITANEN J, AUVINEN A, ISOLA J et al. Female predominance in meningeomas can not be explained by differances in progesterone, estrogen, or androgen receptor expression. J Neurooncol 2006; 80: 1-7. http://dx.doi.org/10.1007/s11060-006-9146-9

[3] ALAHMADI H, CROUL SE. Pathology and genetics of meningiomas. Semin Diagn Pathol. 2011;28: 314-324. http://dx.doi. org/10.1053/j.semdp.2011.01.002

[4] RIEMENSCHNEIDER MJ, PERRY A, REIFENBERGER G. Histological classification and molecular genetics of meningiomas. Lancet Neurol 2006; 5: 1045-1054. http://dx.doi. org/10.1016/S1474-4422(06)70625-1

[5] ABRAMOVICH CM, PRAYSON RA. Histopathologic features and MIB-1 labeling indices in recurrent and nonrecurrent meningiomas. Arch Pathol Lab Med 1999; 123: 793-800.

[6] DEVAPRASATH A, CHACKO G. Diagnostic validity of the Ki-67 labeling index using the MIB-1 monoclonal antibody in the grading of meningiomas. Neurol India 2003; 51: 336-340.

[7] ROSER F, SAMII M, OSTERTAG H, BELLINZONA M. The Ki-67 proliferation antigen in meningiomas. Experience in 600 cases. Acta Neurochir 2004; 146: 37-44. http://dx.doi. org/10.1007/s00701-003-0173-4

[8] COMMINS DL, ATKINSOM RD, BURNETT ME. Review of meningeoma histopathology. Neurosurg Focus 2007; 23: 1-9.
[9] BRUNA J, BRELL M, FERRER I, GIMENEZ-BONAFE P, TORTOSA A. Ki-67 proliferative index predicts clinical outcome in patients with atypical or anaplastic meningioma. Neuropathology 2007; 27: 114-120. http://dx.doi.org/10.1111/ j.1440-1789.2007.00750.x

[10] BARBARESCHI M, IUZZOLINO P, PENNELLA A ALLEGRANZA A, ARRIGONI G, et al. P53 protein expression in central nervous system neoplasms. J Clin Pathol 1992; 45: 583-586. http://dx.doi.org/10.1136/jcp.45.7.583

[11] CHO H, HA SY, PARK SH, PARK K, CHAE YS. Role of p53 gene mutation in tumor aggressiveness of intracranial meningiomas. J Korean Med Sci 1999; 14: 199-205.

[12] ABRY E, THOMASSEN IØ, SALVESEN ØO, TORP SH. The significance of Ki-67/MIB-1 labeling indeks in human meningiomas: A literature study. Pathol Res Pract 2010; 206: 810-815. http://dx.doi.org/10.1016/j.prp.2010.09.002

[13] AGUIAR PH, AGNER C, SIMM R, FREITAS AB, TSANACLIS $\mathrm{AM}$, et al. $\mathrm{P} 53$ protein expression in meningiomas-clinicopathologic study of 55 patients. Neurosurg Rev 2002; 25: 252-257. http://dx.doi.org/10.1007/s10143-002-0204-2

[14] MASHIYAMA S, MURAKAMI Y, YOSHIMOTO T, SEKIYA T, HAYASHI K. Detection of p53 gene mutation in human brain tumors by single-strand conformation polymorphism analysis of polymerase chain reaction products. Oncogene 1991; 6: 1313-1318.

[15] BIROS E, KALINA I, KOHUT A, BOGYIOVA E, SALAGOVIC J, et al. Allelic and haplotype frequencies of the p53 polymorphisms in brain tumor patients. Physiol Res 2002; 51: 59-64.

[16] ALMEIDA LO, CUSTODIO AC, PINTO GR, SANTOS MJ, ALMEIDA JR et al. Polymorphism and DNA methylation of gene TP53 associated with extra-axial brain tumors. Genet Mol Res 2009; 8: 8-18. http://dx.doi.org/10.4238/vol81 gmr518

[17] AL-KHALAF HH, LACH B, ALLAM A, ALKHANI A, ALROKAYAN SA, et al. The p53/p21 DNA damage-signaling pathway is defective in most meningioma cells. J Neurooncol 2007; 83: 9-15. http://dx.doi.org/10.1007/s11060-006-9301-3

[18] OZEN O, DEMIRHAN B, ALTINORS N. Correlation between histological grade and MIB-1 and P53 immunoreactivity in meningiomas. Clin Neuropathol 2005; 24: 219-224.

[19] RAO S, SADIYA N, DORAISWAMI S, PRATHIBA D. Characterization of morphologically benign biologically aggressive meningiomas. Neurol India 2009; 57: 744-748. http://dx.doi. org/10.4103/0028-3886.59470

[20] TERZI A, SAGLAM EA, BARAK A, SOYLEMEZOGLU F. The significance of immunohistochemical expression of Ki67, p53, p21 and p16 in meningiomas tissue arrays. Pathol Res Pract 2008; 204: 305-314. http://dx.doi.org/10.1016/ j.prp.2008.01.013

[21] PERRY A, STAFFORD SL, SCHEITHAUER BW, SUMAN VJ, LOHSE CM. The prognostic significance of MIB-1, p53 and DNA flow cytometry in completely resected primary meningiomas. Cancer 1998; 82: 2262-2269. http://dx.doi. org/10.1002/(SICI) 1097-0142(19980601)82:11<2262::AIDCNCR23>3.0.CO;2-R 